\title{
DEVELOPMENT OF MIRROR SPECIFICATIONS
}

\author{
M. A. Lind \\ Pacific Northwest Laboratory*, Richland, WA 99352
}

\section{Introduction}

This report highlights the work performed by PNL for Sandia Laboratories under a contract titled "Survey and Analysis of Mirror Silvering Technology and Heliostat Glass Evaluation", funded at $\$ 164 \mathrm{~K}$ for FY 79 . The primary purpose for the work was to develop specifications that will enhance the durability and lifetime of heliostat mirrors.

The contract was initiated with a technical survey of the present commercial silvered glass mirror industry and an analytical investigation of the degradation phenomena experienced by the heliostat mirrors at Sandia's Livermore test facility. The main thrust was to evaluate the present methods of silver deposition and protection in order to recommend a specification for the heliostat mirror silvering process that would extend the lifetime of the Barstow mirror field. In addition, several advanced concepts for enhancing mirror lifetime were investigated. Technical and measurement support for evaluation of the Barstow heliostat glass and updating the glass specification was also provided.

Only a brief overview of the mirror survey and analysis is presented here. The reader is referred for details to the final report entitled "Heliostat Mirror Survey and Analysis" scheduled for release later this month.

\section{Mirror Manufacturing Process}

Figure 1 shows the structure of a commercial second surface glass silvered mirror. The silver is deposited on the non-tin side of the glass. The nominal thickness of the silver layer is $70 \mathrm{mg} / \mathrm{ft}^{2}(700 \AA)$. There is some evidence to suggest that the layer may be 10-20\% lower in density than the metal itself would allow. The copper overcoat is nominally $25 \mathrm{mg} / \mathrm{ft}^{2}$ $(300 \AA)$ in thickness. The state purpose of the copper is to provide protection for the silver as a sacrificial layer and to provide stress relief and better adhesion between the silver and paint layers. The paint layer is nominal1y $6-10 \mathrm{~g} / \mathrm{ft}(0.001 \mathrm{in.})$ thick and serves to provide abrasion protection during handling and shipping. The paint layer is formulated like an automotive primer. It is relatively porous to allow for escape of entrapped gasses and water vapor during processing. It is also relatively brittle to allow for easy post process cutting. It is not, nor is it claimed to be, a good moisture barrier.

The actual processing steps for a typical mirror production line are shown in Figure 2. The glass is hand loaded onto a continuous production line. It is abrasively scrubbed with a $\mathrm{CO}_{2}$ paste and then rinsed. It is

* Operated by Battelle Memorial Institute for the Department of Energy under Contract EY-76-C-06-1830. 


\section{DISCLAIMER}

This report was prepared as an account of work sponsored by an agency of the United States Government. Neither the United States Government nor any agency Thereof, nor any of their employees, makes any warranty, express or implied, or assumes any legal liability or responsibility for the accuracy, completeness, or usefulness of any information, apparatus, product, or process disclosed, or represents that its use would not infringe privately owned rights. Reference herein to any specific commercial product, process, or service by trade name, trademark, manufacturer, or otherwise does not necessarily constitute or imply its endorsement, recommendation, or favoring by the United States Government or any agency thereof. The views and opinions of authors expressed herein do not necessarily state or reflect those of the United States Government or any agency thereof. 


\section{DISCLAIMER}

Portions of this document may be illegible in electronic image products. Images are produced from the best available original document. 
then sensitized with a SnCl and acid solution and rinsed again. The silver is applied as a multi-solution spray consisting of a silver-ammonia complex, a caustic, and an aldehyde reducer. This is followed by another rinse before the application of the copper layer. The copper solution $\left(\mathrm{CuSO}_{4}\right)$ is reduced in a galvanic reaction by an iron filing slurry. The sheet is dried and painted using a curtain coater. The paint is heated for rapid curing. The mirror is then cleaned and packed.

\section{Experimental Results}

A large amount of experimental and analytical data has been collected to attempt to define and control mirror degradation and aid in the formulation of a specification for mirrors. Some of the more interesting results are discussed briefly below:

There is evidence to suggest that the copper and silver layers tend to diffuse into one another. An Auger Electron Spectroscopy (AES) sputter depth profile through the copper and silver layers is shown in Figure 3. The AES technique samples only a few monolayers at a time. The probing beams as narrow as $1000 A$ in diameter show similar results indicating that sample roughness on that dimensional scale is not what is causing the apparent intermixing. AES beams. as small as $200 \AA$ will be used to confirm the results. The results support the thes is that degradation of the mirror coe to separation of the copper and silver layers is unlikely.

It is well known that a thin silver coating tends to agglomerate when heated. SEM photographs of such behavior for commercially produced wet process silver mirrors are shown in Figure $4 a$. The photo shows the extent of agglomeration after 30 minutes at $200^{\circ} \mathrm{C}$. The agglomeration becomes more severe as the temperature is increased. Its effect on the mirror reflectivity is shown in the accompanying graph in Figure 4b. Although some improvement in reflectance is apparent up to $150^{\circ} \mathrm{C}$, temperatures beyond $150^{\circ} \mathrm{C}$ lead to lower performance mirrors. The $350^{\circ} \mathrm{C}$ mirror was nearly transparent. This result has profound implications for any concepts which require high temperatures to environmentally seal the mirrors. Further studies on the kinetics and deposition parameter dependence of this phenomena are underway.

The thickness of the silver and copper layers should have some effect on the mirror reflectivity. While no significant dependence on the thickness of the copper layer was found regardless of the thickness of the silver layer, the effect of the thickness of the silver.layer on reflectivity is significant. Experimental results showing reflectance versus silver thickness $\left(100 \mathrm{mg} / \mathrm{ft}^{2} \cong 100 \AA\right)$ for a variety of deposition techniques is shown in Figure 5 . The samples used for this investigation were manufactured by London Laboratories. (a major chemistry supplier) at their Connecticut laboratory. While the results depend somewhat on the deposition process, it appears the minimum desirable silver thickness is approximately $75 \mathrm{mg} / \mathrm{ft}^{2}$.

Numerous analytical surface examination techniques have been used to examine degraded mirrors obtained from the Sandia Livermore test facility and various inirror companies. Visually, the degraded Sandia mirrors show a hazy or spotted appearance. In general both types of degradation appear 
to originate in a similar manner. Water is thought to play a large roll in the degradation process, but recent work indicates it may not be the whole story. The actual wet chemistry process of depositing the silver may be initiating the degradation. A theoretical mechanism in which the residual hydrogen ions on the surface glass attack the silica structure leading to a loss of adhesion between the silver and the glass has been proposed.

Figure 6 shows a slice of a nondegraded region of the degraded Sandia mirror. The silver/copper/paint layer has physically separated from the glass. This type of degradation is not uncommon. It is not known, however, whether this phenomena leads to the larger visible degradation seen on the Sandia mirror. More experimental work is necessary to verify the degradation mechanism. Some of these experiments are underway and are described in the report.

Mirror degradation can be accelerated by inserting the mirror in boiling water. Figure 7 shows an SEM photograph of a commercial mirror with no paint backing (glass, silver and copper only) that has been placed in boiling deionized water for 3 hours. The copper/silver layer gradually peeled away leaving the glass surface. Silver nodules approximately. $700 . \AA$ in diameter which are spaced about $1000 \AA$ apart remain on the glass surface near the peeling metal edge. As the peeling progresses the nodules are further exposed to the hot water. They gradually disappear. The presence of the nodules supports the thes is that the silver adheres most strongly to the tin islands deposited during the sensitization step. The sample demonstrates that a simple boiling water test may be a useful screening tool for mirror durability. More work is necessary to verify these conclusions.

Assuming the proposed degradation mechanism is accurate, possible solutions to the problem of mirror deterioration can be formulated. One such solution is being actively investigated. An additive which can be included in the present mirroring process with little or no additional equipment appears to inhibit the degradation at the silver-glass interface. Mirrors produced at PNL using the additive have shown very promising, however preliminary, results. These mirrors have withstood 8 hours of boiling deionized water without significant degradation. The specifics of the additive cannot be revealed due to patent considerations, but should be available in the near future.

In an effort to define the best possible mirror for the Barstow heliostat field, the understanding obtained from the industry survey has been convoluted with the experimental results into a preliminary specification for chomically silvered second surface mirrors. While much experimental work remains to be done before a complete understanding of the degradation problem is obtaincd and a positive solution proposed, this specification serves the interim goals of obtaining the best performance and longest life expectancy from mirrors produced using the existing commercial technology. 
Acknowledgments

The author wishes to acknowledge J. S. Hartman, C. Q. Buckwalter, J. L. Daniel, M. T. Thomas, and L. R. Peterson for their contributions to this report. 
MATERIAL QUANTITY

(EST. TYPICAL VALUE)

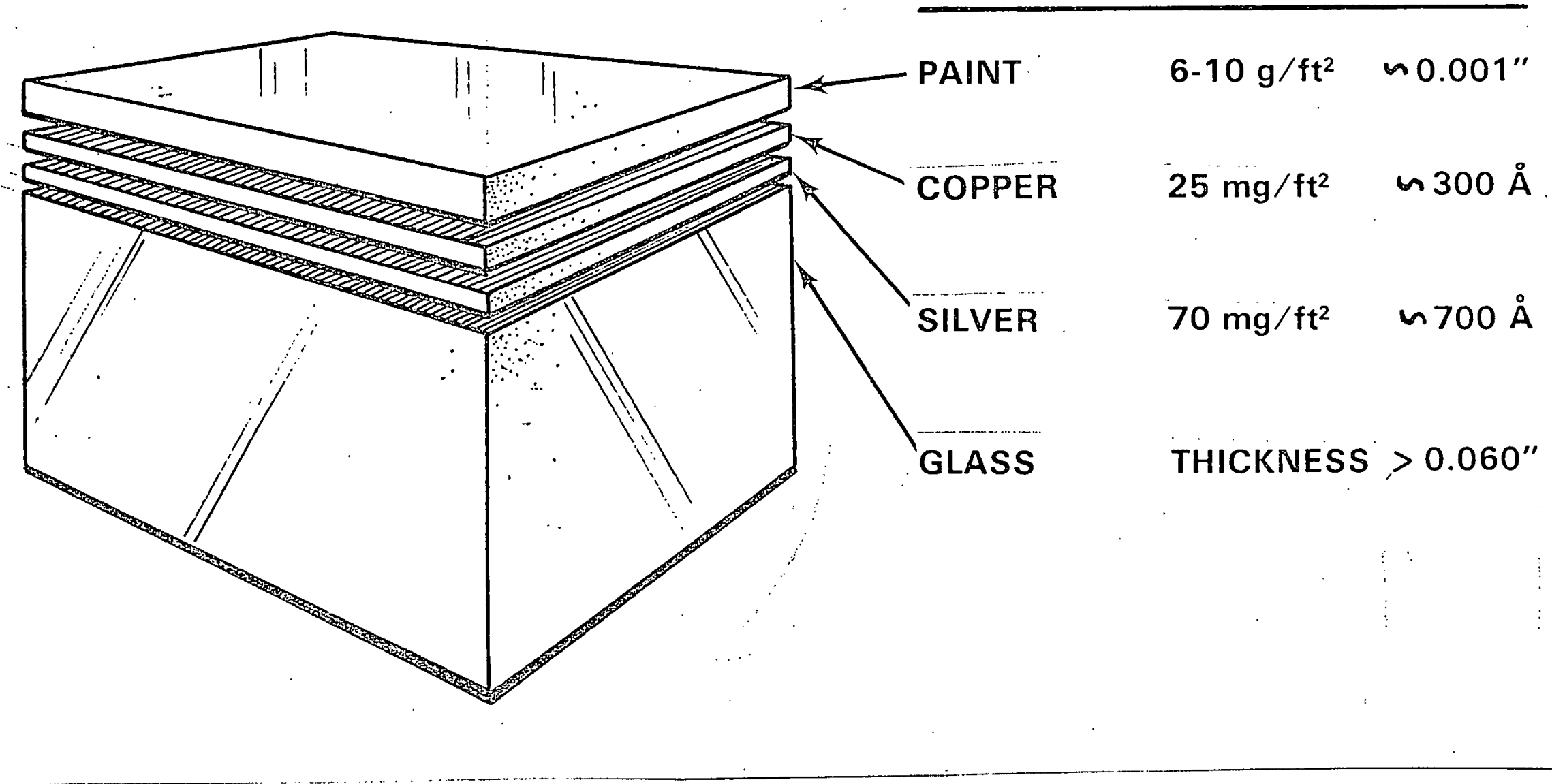

FIGURE 1. Mirror Structure 


\section{MIRROR PRODUCTION SEQUENCE}

\section{PART SILVER SOLUTION/COPPER APPLICATION WITH IRON SLURRY}
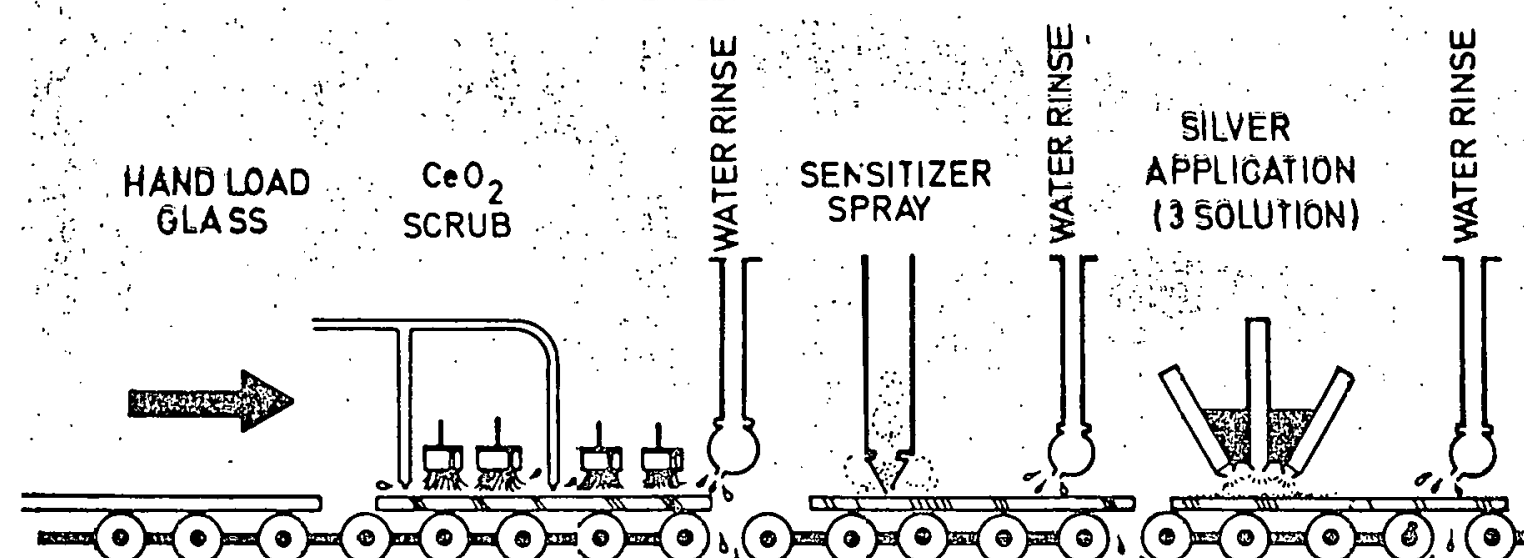

IRON COPPER
FILING APPLICATION

AIR JET

DRYER
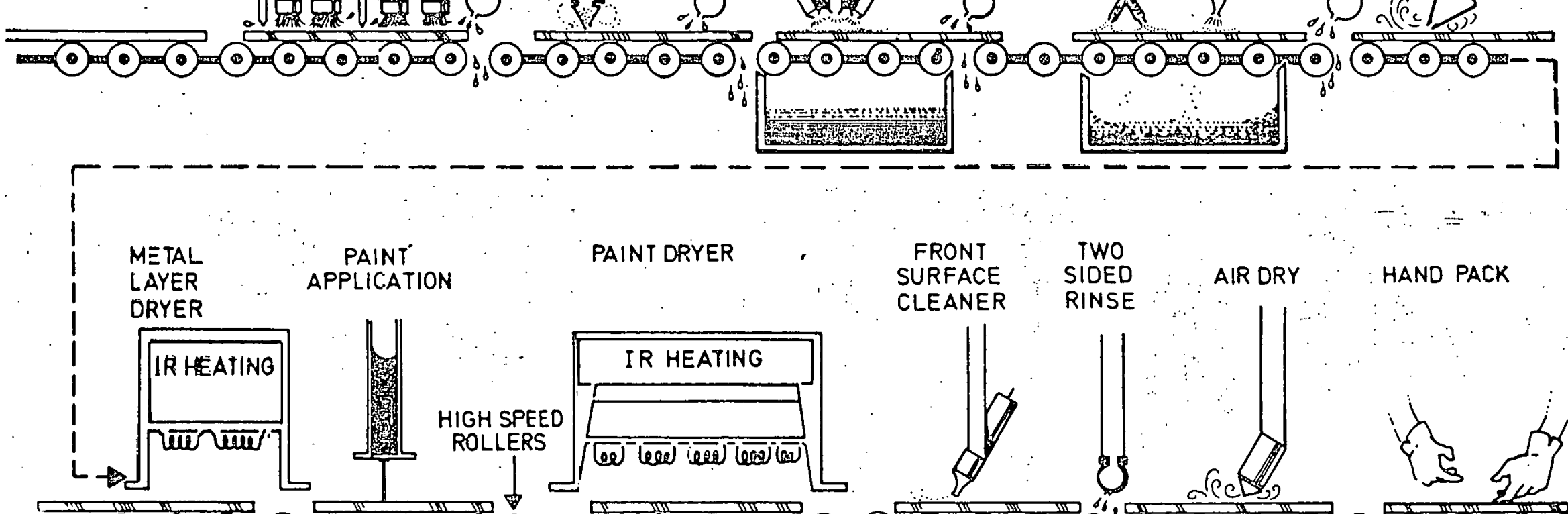

$\therefore$ (0)

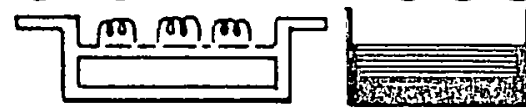

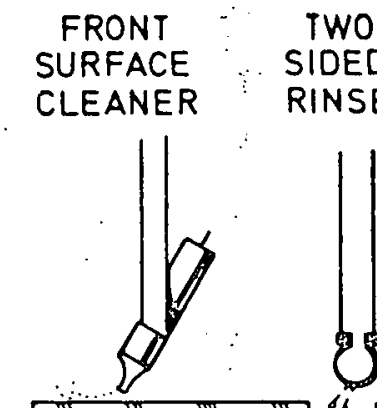

AIR DRY : HAND PACK
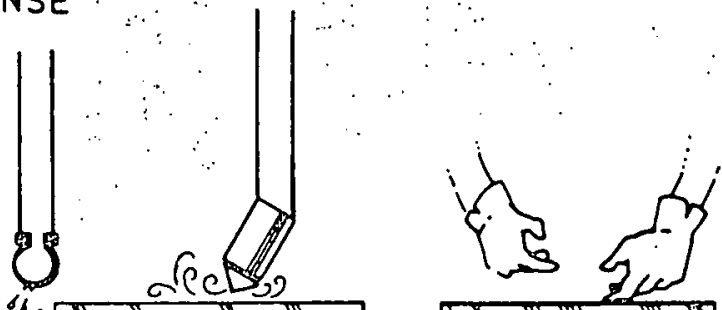

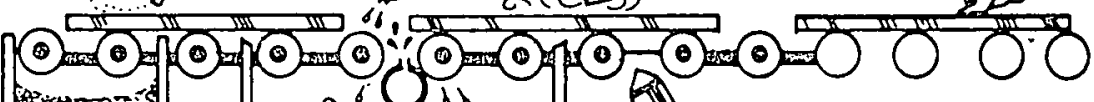

(NOT TO SCALE)

FIGURE 2. Processing Steps for Mirror Production 


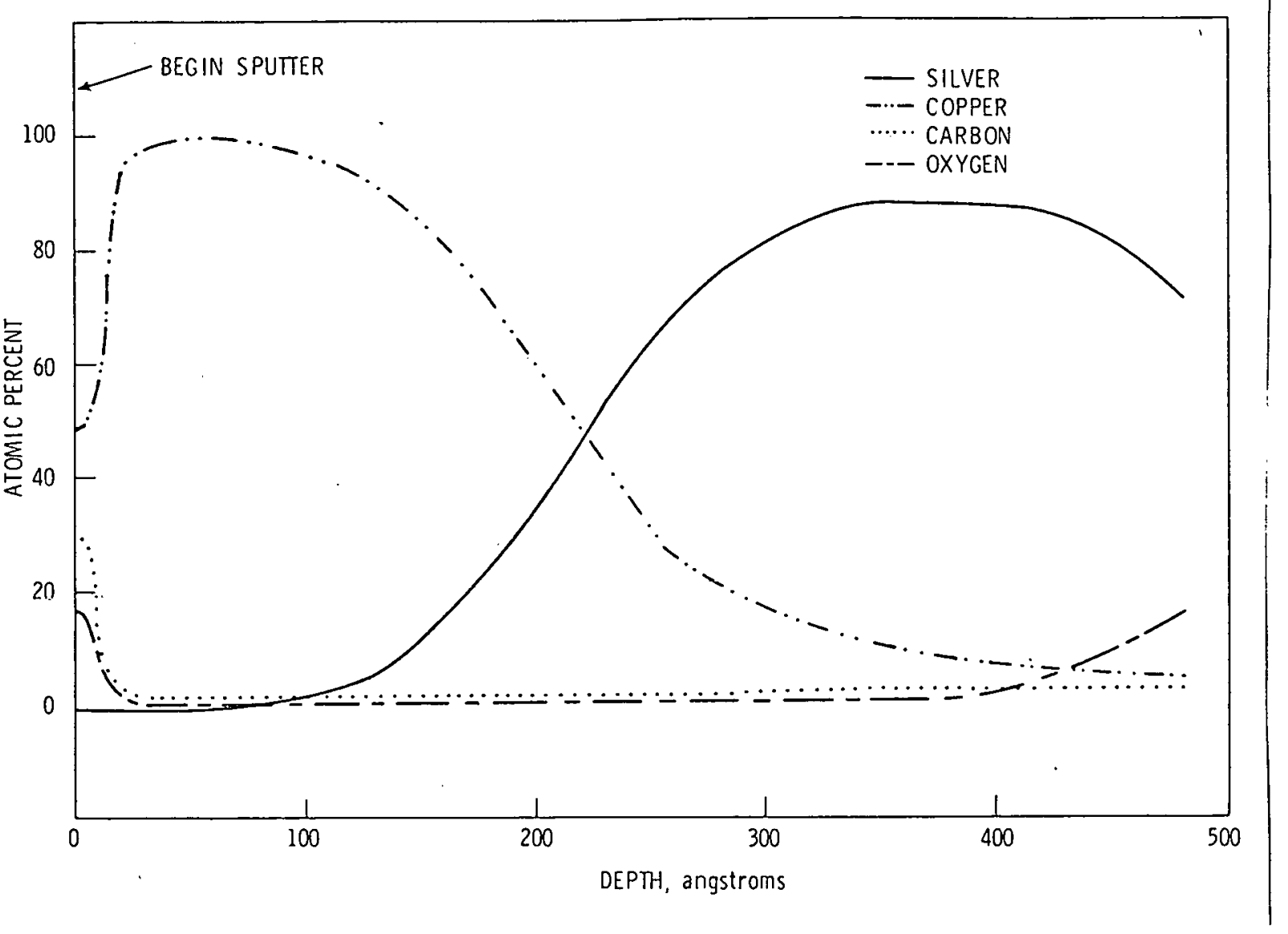

FIGURE 3. AES Sputter Depth Profile of Metallic Layers 

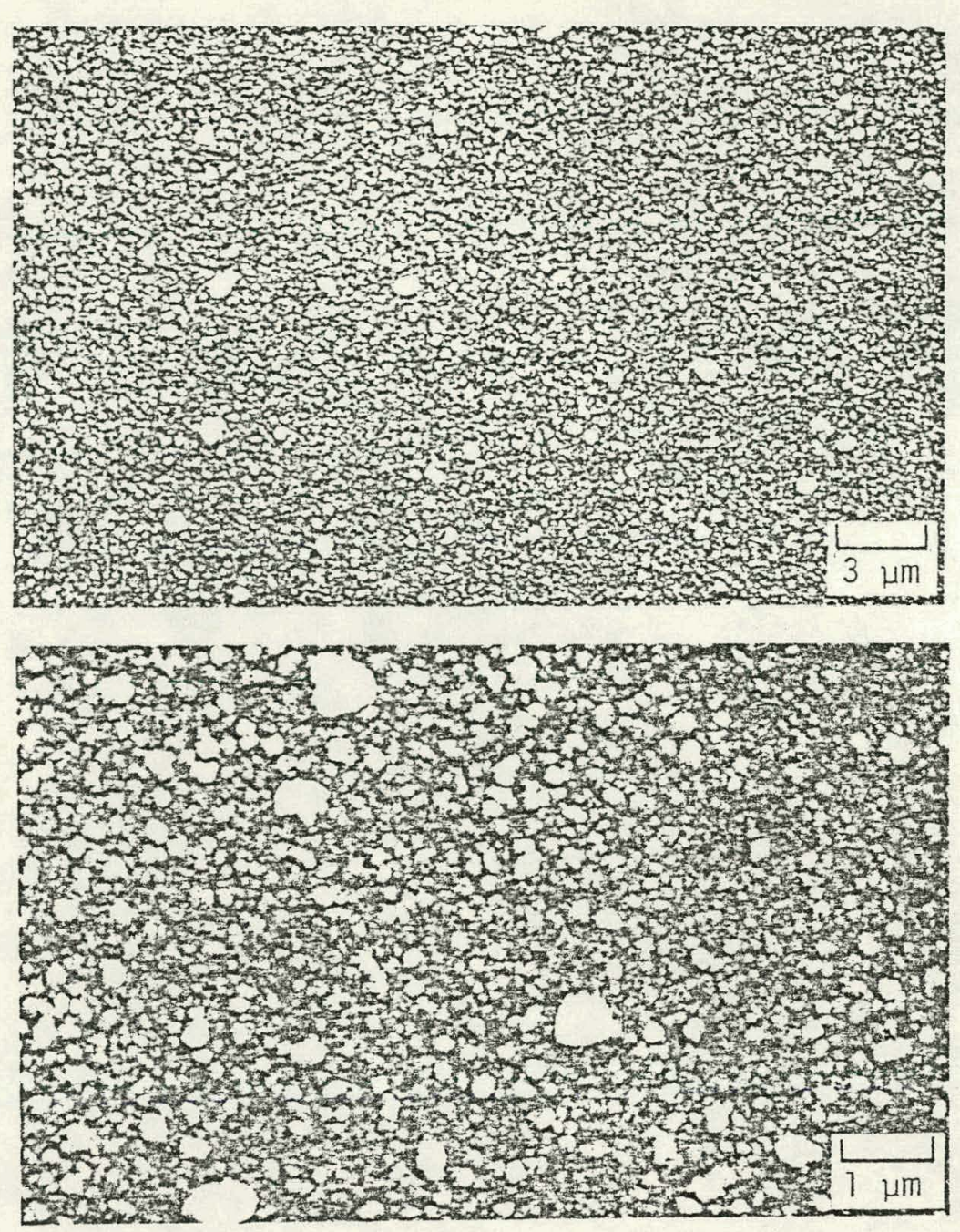

FIGURE 4a. SEM Photograph of Silver Agglomeration for a Wet Process Deposited Silver Mirror Heated to $200^{\circ} \mathrm{C}$ for $30 \mathrm{Min}$. 


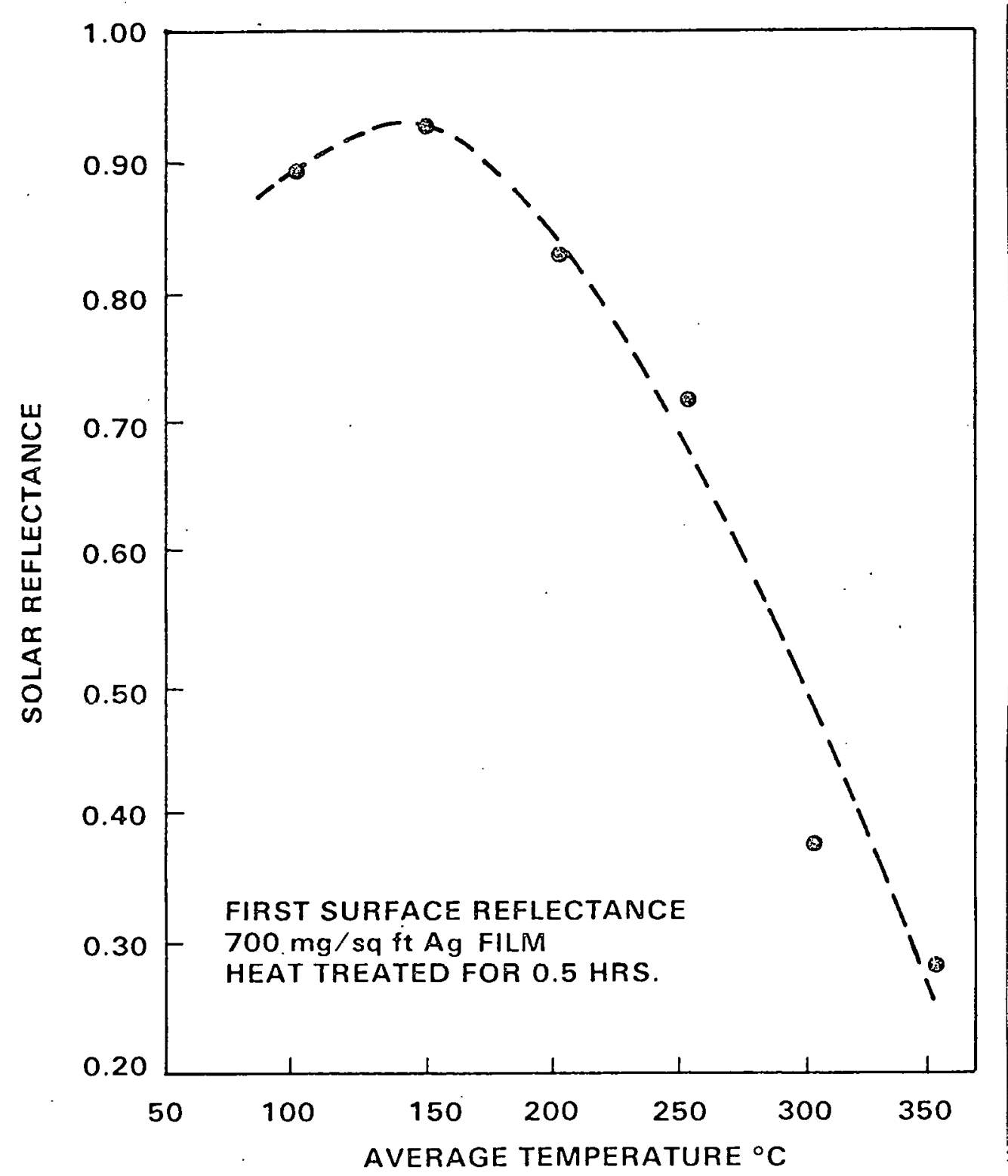

FIGURE 4b. Solar Reflectance Versus Aging Temperature for a Chemically Deposited Solar Mirror 
GLASS/SILVER SECOND SURFACE MIRROR

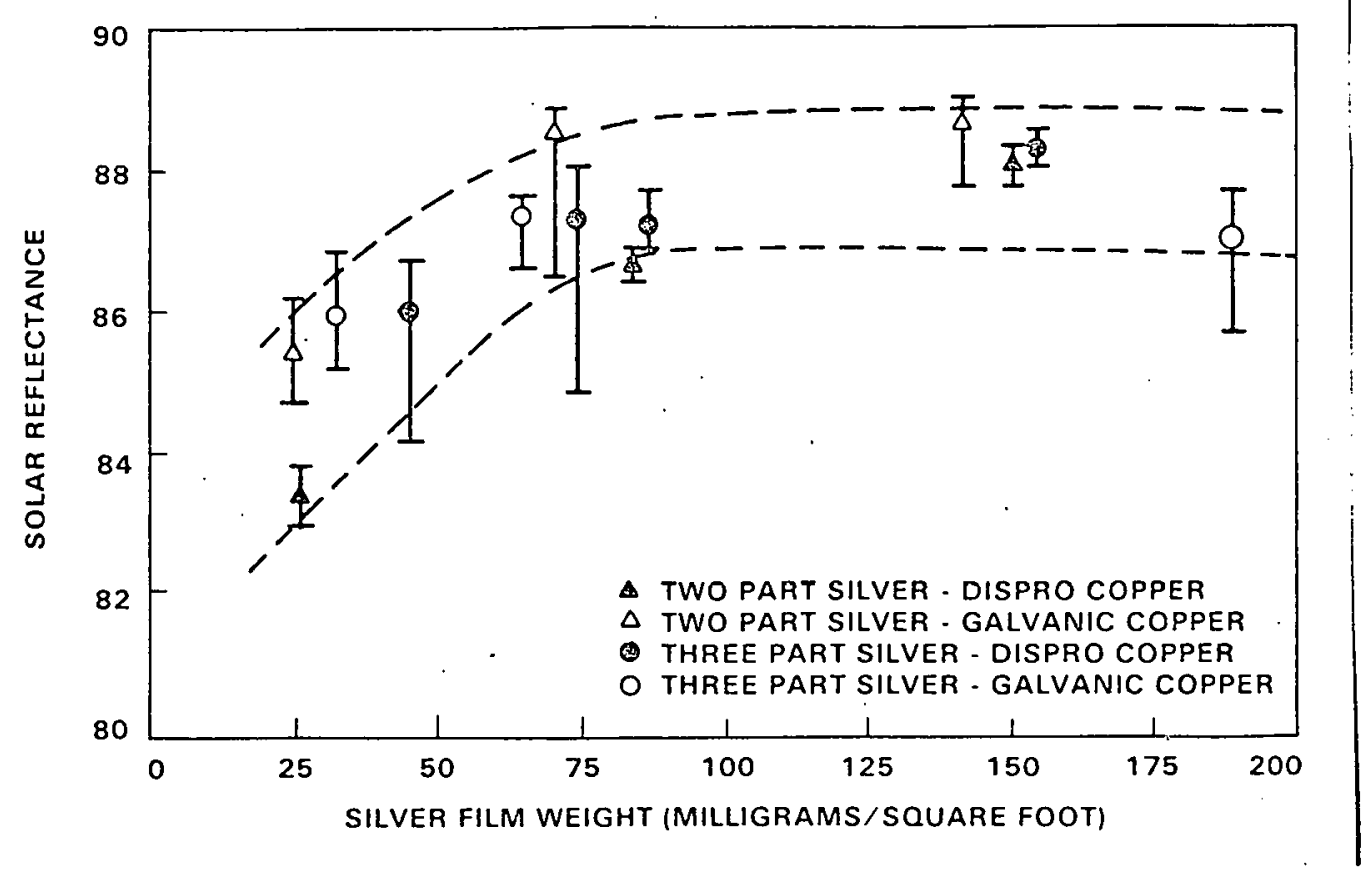

FIGURE 5. Solar Reflectance Versus Film Thickness for Various Silver and Copper Deposition Techniques 

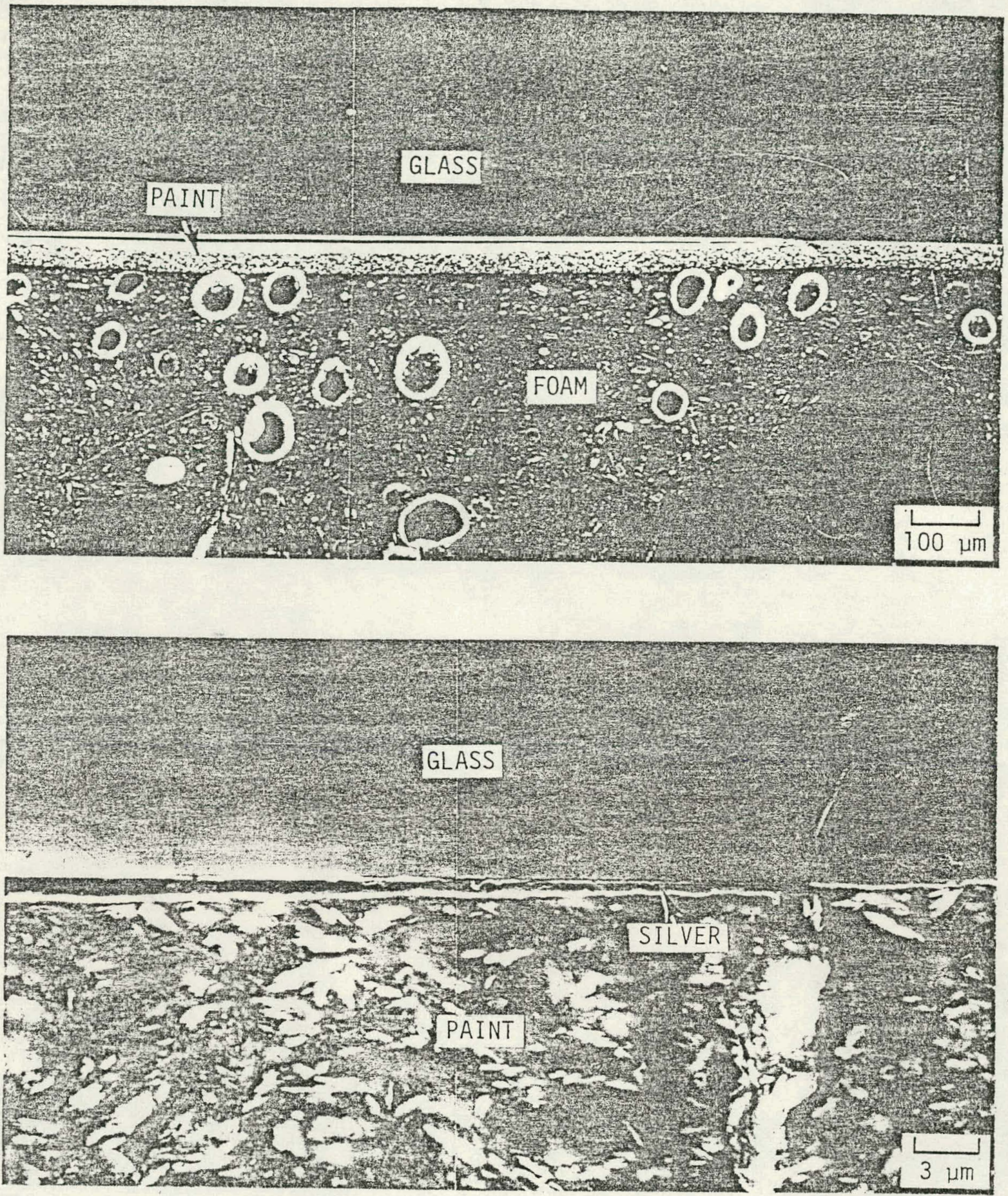

FIGURE 6. SEM Micrographs Showing the Separation of the Silver/Copper/Paint Layer from the Glass Surface 


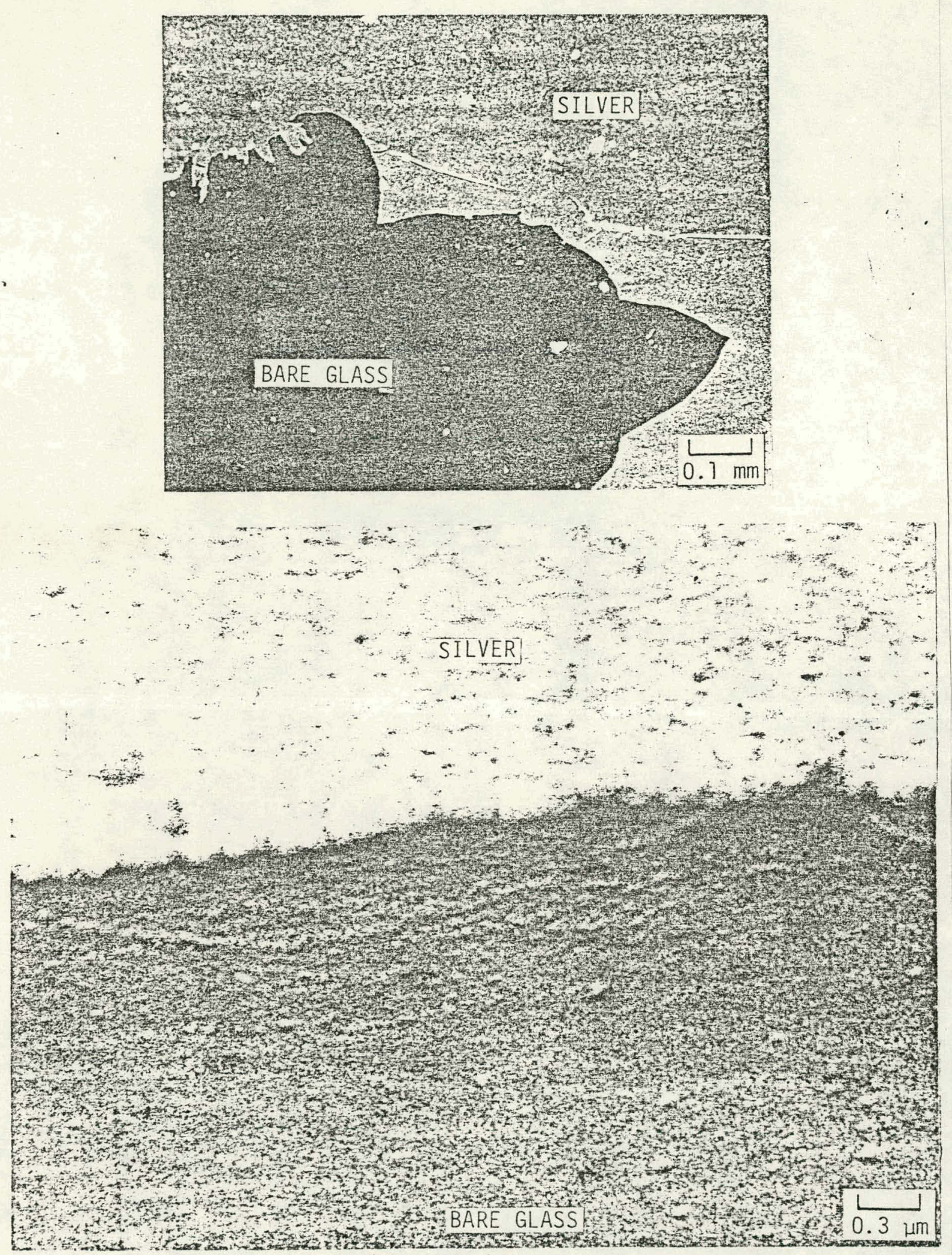

FIGURE 7. SEM Micrographs Showing the Edge of the Metallic Layers Which Remain on the Glass Substrate after Three Hours in a Bonding Deionized Water Bath 


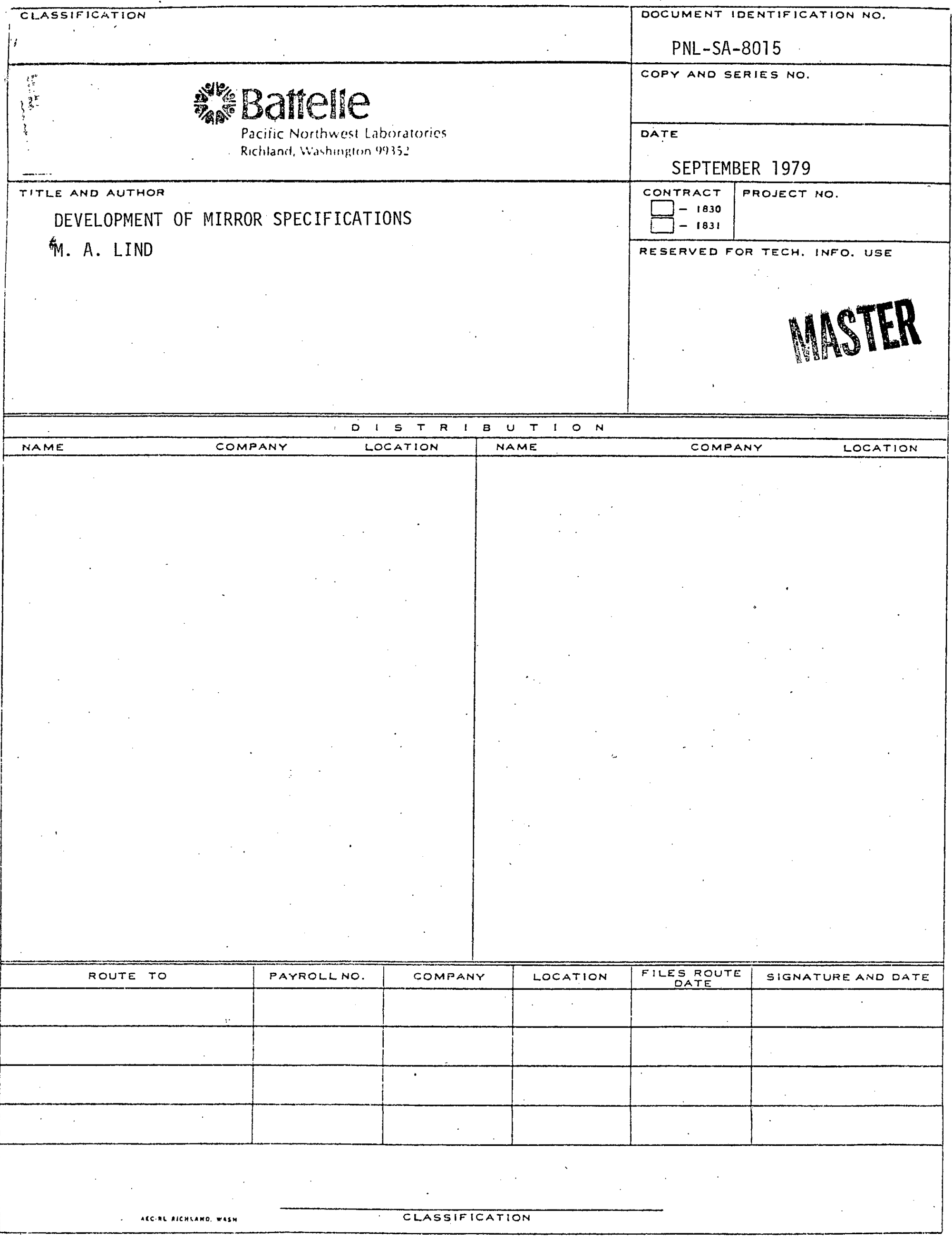

